\title{
Modeling and Load Flow Analysis of a Microgrid Laboratory
}

\author{
Taufik*, Matthew A. Guevara, Ali Shaban and Ahmad Nafisi
}

\begin{abstract}
Microgrids-miniature versions of the electrical grid are becoming increasingly more popular as advancements in technologies, renewable energy mandates, and decreased costs drive communities to adopt them. The modern microgrid has capabilities of generating, distributing, and regulating the flow of electricity, capable of operating in both grid-connected and islanded (disconnected) conditions. This paper utilizes ETAP software in the analysis, simulation, and development of a lab-scale microgrid located at Cal Poly State University. Microprocessor-based relays are heavily utilized in both the ETAP model and hardware implementation of the system. Three case studies were studied and simulated to investigate electric power system load flow analysis of the Cal Poly microgrid. Results were compared against hardware test measurements and showed overall agreement. Slight discrepancies were observed in the simulation results due mainly to the non-ideality of actual hardware components and lab equipment.
\end{abstract}

Index Terms: microgrid, power engineering laboratory, ETAP modeling, power system education.

\section{INTRODUCTION}

$\mathrm{M}$ icrogrids as the scaled down versions of our electrical grid are becoming increasingly more popular as greater energy independence and extreme weather conditions drive communities to adopt them. Conventionally, electrical power is delivered by utilities from large power generating stations far away from end users, transmitted across long distances, and ultimately distributed to meet the customers' electrical needs. Advancements in technologies, decreased costs, and renewable energy mandates are shifting the power industry away from this centralized generation model. Instead, utilities are observing their customers not only as energy consumers but also actively producing electrical power. The modern microgrid has capabilities of generating, distributing, and regulating electrical power locally, utilizing distributed energy resources (DERs) situated close to end users, including smaller power sources such as photovoltaics (solar) and battery energy storage systems to meet the electrical demands of the customer.

Manuscript received July 11, 2019; revised September 10, 2019; accepted October 15, 2019.

Taufik is with Electrical Engineering Department, Cal Poly State University, San Luis Obispo, USA (e-mail: taufik@ @alpoly.edu).

Matthew A. Guevara, Ali Shaban and Ahmad Nafisi Electrical Engineering Department, Cal Poly State University, San Luis Obispo, USA (e-mail: \{maguevar, ashaban, anafisi\}@ calpoly.edu).

*Corresponding author.
The microgrid has capabilities of operating in both gridconnected and islanded modes - that is, connected or disconnected from the larger electrical grid, respectively. From the customer perspective, this presents several advantages - for example, if a power outage were to occur on the main grid due to natural disasters or electrical faults, the microgrid can island from the grid and continue its generation and distribution of local power. Additionally, if the microgrid requires additional generation to meet the demands of the customer, the microgrid can reconnect with the main grid to help supplement the customers' energy needs.

From the utility perspective, transitioning the microgrid from grid-connected to islanded conditions presents both advantages and disadvantages. A 2014 survey of over 250 utility executives concluded "...utilities said they find current interconnection standards inadequate for safety purposes, with 54\% of utilities surveyed finding that to be the case" [1]. As microgrids continue to rise in popularity, it is imperative to study and implement reliable and robust protection schemes as microgrids transition between gridconnected and islanded conditions. Nonetheless, reference [2] claims "microgrids deployment of controllable resources, such as dispatchable generation units, energy storage, and adjustable loads, provides a quick and efficient response for changing the microgrid generation/load, which can be utilized for supporting the grid operation." Maintaining the balance between power supply and load has become problematic for utilities in recent years. Microgrids can be implemented to help control and supplement the supply-load balance by offering storage and generation services to the main grid.

Figure 1 shows a net load graph by California ISO (CAISO), displaying the net load in 2013 and forecasted future net loads [3]. The net load curves indicating years 2014-2020 can be interpreted as the net power needed to be supplied to California's customers from all sources of electrical power other than from renewables. The lowest points on the curve (the belly of the "duck") represents a point in which renewable generation is at a maximum. Data indicates that risks of over generation and necessary ramping power is increasing in future years largely due to growing solar photovoltaic proliferation onto the grid. Currently, grid operators need to closely monitor these curves and curtail or dispatch electrical power as needed. Microgrids can be utilized to help "flatten" this duck curve to maintain the supply-load balance and retain grid reliability in several ways. For example, when renewable penetration is at a maximum leading to risks of over generation, the microgrid can store excess energy with a battery energy storage system. As the sun begins to set after $4 \mathrm{pm}$ and aggregate solar penetration to the main grid begins to decrease, microgrids 
can help supply the necessary ramping power needed to meet the electrical demand of California's customers.

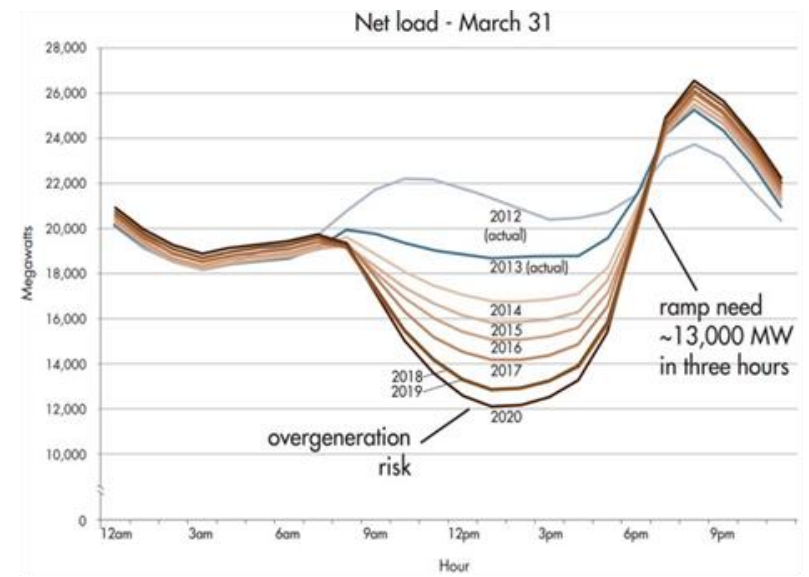

Fig. 1. The CAISO duck chart for 2013.

Figure 2 showcases the opportunities ahead for utilities, based on a survey of over 250 utility executives in 2014 [1]. A staggering $97 \%$ of utility executives believe microgrids are a viable business opportunity within the next 10 years, with a majority of utilities already developing or planning to operate microgrids within the same timeframe.
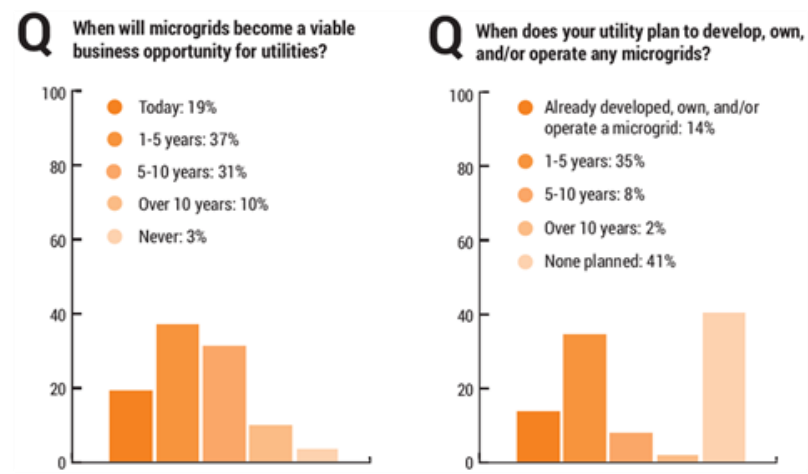

Fig. 2. The opportunities ahead: Utilities

Microgrids are an inevitable reality — critical loads such as hospitals, data centers, and military bases can benefit greatly from increased reliability of electric power in both grid-connected and islanded conditions. Microgrids can also support grid operation by storing and dispatching electrical energy as necessary. It is then imperative for future power system engineers to expand their knowledge on fundamental power system components such as generators, transformers, and protective relaying to account for emerging technologies onto the grid.

\section{Microgrid MODELING AND STABILITY ANALYSIS}

Future trends of developing microgrids and their integration with the utility grid necessitate adequate tools for modeling and analysis purposes. In response for "facing a rapidly-changing power industry, the electrical engineering department at Cal Poly State University proposed Advanced Power Systems Initiatives to better prepare its students for entering the power industry" [4]. One effort to accomplish as presented in this paper is the development of the foundation for a lab-scale microgrid laboratory. To ultimately implement a microgrid capable of islanding capabilities, it is imperative to first develop an adequate model of the microgrid and perform a system stability analysis.

Figure 3 displays the single-line diagram of the bidirectional network designed and implemented in a laboratory environment for the proposed lab [4], which is to be utilized as the basis for the microgrid. The network represents two different radial power systems coupled together at bus 3 . In this configuration multiple sources of power supply the loads at bus 3 , which include the induction motor and static loads. The power is supplied by three-phase AC voltages, modeled as infinite buses in Figure 3, ultimately supplied by the utility. Common power system components including power transformers and transmission lines are implemented, as well as resistors to limit the total current flowing in the systems.

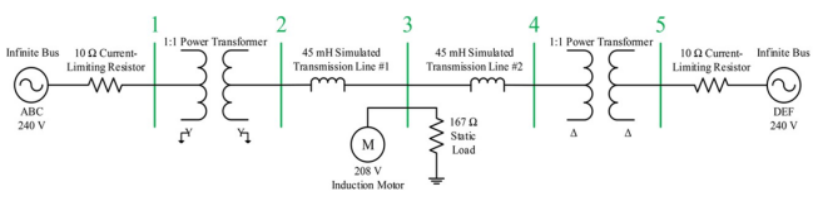

Fig. 3. Bidirectional network single-line diagram

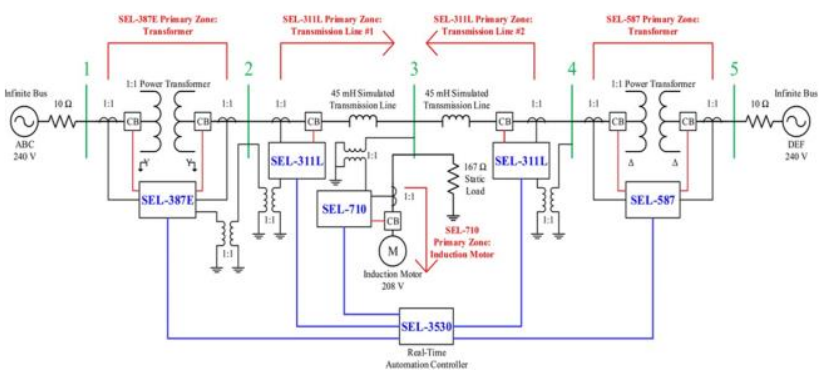

Fig. 4. Bidirectional network single-line protection diagram.

Figure 4 displays the existing protective elements within the bidirectional network [4], completed in May 2017. Microprocessor based SEL (Schweitzer Engineering Laboratories) protective relays are constantly measuring power system parameters such as voltages and currents, ultimately sending trip signals to nearby circuit breakers to protect nearby components in the event of a disturbance such as a fault. The SEL relays are programmed to trip circuit breakers on parameters such as the type of fault, equipment and zone of protection, and protection coordination between relays.

The future microgrid will additionally include other DERs such as photovoltaics and battery storage systems. As the microgrid expands in complexity with added equipment and functionality, it is necessary to develop an adequate model of the system. ETAP is a power system modeling, analysis, and optimization software. ETAP enables its users with several tools to accurately model power systems that will ultimately benefit the microgrid project moving forwards. For example, ETAP network analysis tools include standard load flow, short circuit, motor acceleration, and harmonic analysis. Protection and coordination tools include ETAP "STAR" modules to coordinate time-current curves associated with microgrid protective elements.

As the microgrid begins to implement its DERs beginning with additional synchronous generators as shown in Figure 4 , synchronous generator protection and coordination can be adequately modeled in ETAP. Future additional DERs 
appended to Cal Poly's microgrid including photovoltaics and battery storage systems can be sufficiently modeled and analyzed in ETAP. A system analysis will then be performed including load flows, short circuits, and protection coordination studies.

The bidirectional network in Fig. 4 for use as the basis for the microgrid assumed two states - steady or faulted. Power systems are largely imbalanced in nature and consistently undergoing small scale disturbances. Reference [5] defines power system stability as "...the ability of an electric power system, for a given initial operating condition, to regain a state of operating equilibrium after being subjected to a physical disturbance, with most system variables bounded so that practically the entire system remains intact." Power system stability can then be observed as a single problem with many different classifications of instability that can result from various disturbances, with their forms generalized in Fig. 5 [5].

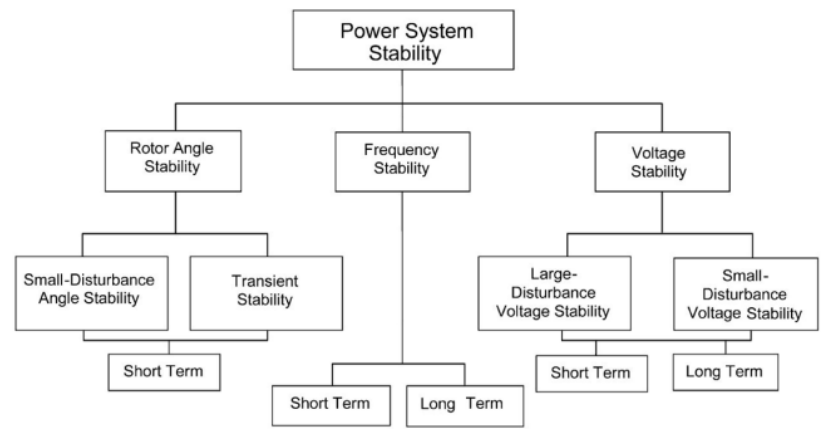

Fig. 5. Classification of power system stability

Stability in a microgrid shares similarities with classical power system stability classifications shown in Fig. 5, with additional issues such as disturbances resulting from islanding. Reference [6] suggests "with micro sources with current limit, very little spinning reserve and limited reactive support, it is essential to carry out detailed transient analysis with possible contingencies," with Fig. 5 showcasing microgrid stability issues. Unlike microgrids with limited resources, the bulk power system typically has excess generating capacity, or operating reserves, to meet real and reactive demands to maintain stability [7][8].

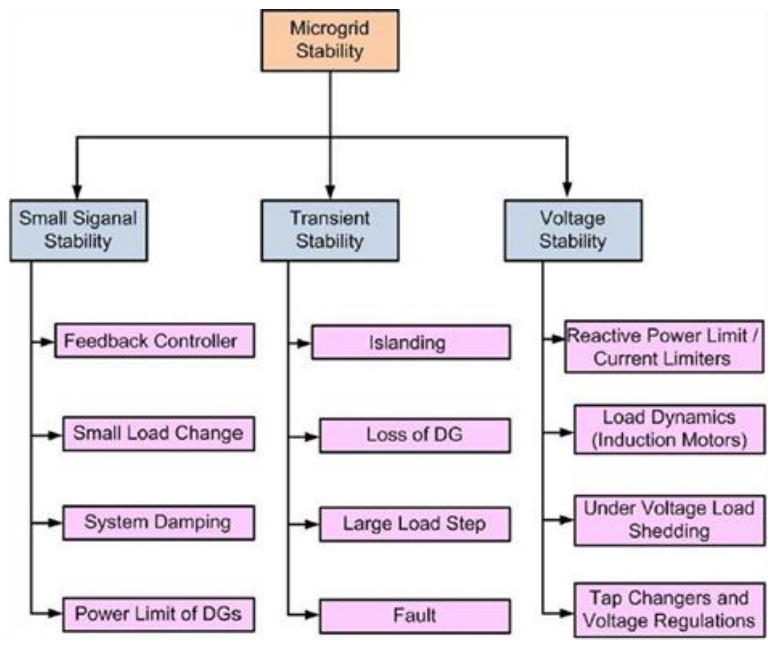

Fig. 6. Different stability issues in microgrid

\section{DESIGN REQUIREMENTS}

Figure 7 shows a level zero block diagram used for developing the ETAP model of the Cal Poly microgrid.

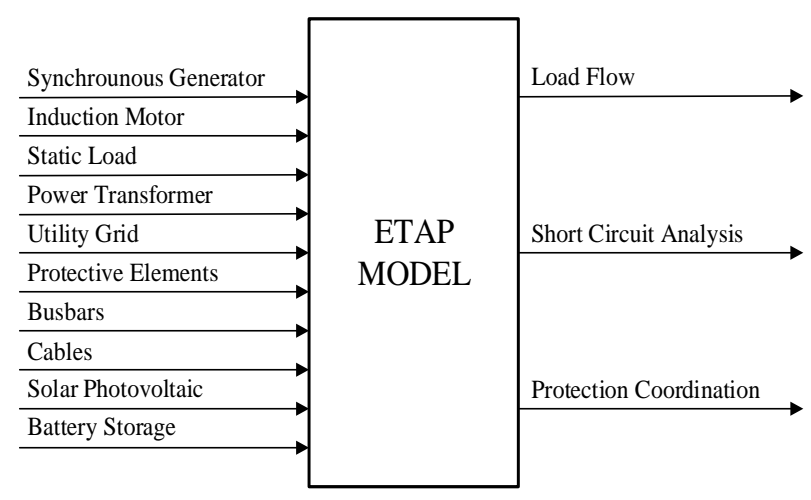

Fig. 7. ETAP model level 0 block diagram

Inputs to the ETAP model block diagram include the entirety of the existing microgrid components including synchronous generators, induction motor, static loads, power transformers, utility grid, protective elements, busbars, and cables. Input devices that are currently not implemented in the existing microgrid include solar photovoltaics and battery storage systems. However, these modules will ultimately be modeled in ETAP to explore and analyze the functionality of the microgrid as the project develops.

Outputs to the ETAP model block diagram in Fig. 7 include load flow, short circuit analysis, and protection coordination. ETAP Load Flow Analysis module will be utilized to determine bus voltages, power factors, currents, and power flows throughout the microgrid system. To determine bus voltages, angles, and power flows, ETAP Load Flow allows several different load flow calculation methods. To perform the load flow study, each calculation method contains different load flow converging characteristics, allowing flexibility to meet the microgrid system parameters including generation, loading conditions, and initial bus voltages [9].

The ETAP Short Circuit analysis program will be utilized to analyze the fault currents for three-phase, line-to-ground, line-to-line, and line-to-line-ground faults in the microgrid. ETAP is able to calculate the total short circuit current contribution from microgrid elements including the synchronous generators, induction motor, and utility connections. ETAP includes both American National Standards Institute/Institute of Electrical and Electronics Engineers (ANSI/IEEE) and International Electrotechnical Commission (IEC) standards to perform its short circuit calculation methods [10].

The microgrid will utilize ETAP Star, the protection and coordination (selectivity) module within ETAP. ETAP Star is equipped with a comprehensive protective device library, able to accurately model protective elements to perform equipment protection and device coordination studies [10]. ETAP Star Time Current Characteristic (TCC) views will be generated to display device characteristic curves. ETAP Star is also capable of determining operating times of protective devices by simulating faults on the one-line diagram. 


\section{DESIGN}

The ETAP Cal Poly microgrid elements in Fig. 8 include the power grid, impedances, circuit breakers, power transformers, three-phase induction motor, static loads, circuit breakers, current transformers (CTs), potential transformers (PTs/VTs), and protective relays. Power system elements not shown in Fig. 8 include future additions such as solar photovoltaics, inverters, and energy storage modules.

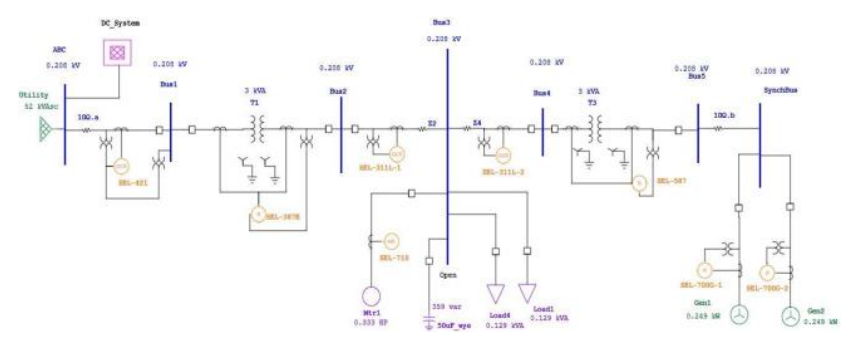

Fig. 8. ETAP one-line view.

The Power Grid element in ETAP models the utility interconnection with the microgrid. The proposed microgrid lab at Cal Poly utilizes 208V, modeled as the utility supply voltage. As such, the Power Grid is rated for $208 \mathrm{~V}$ operating in swing mode. The Power Grid in ETAP is modeled with its Thevenin's equivalent, a constant voltage source behind a short-circuit impedance. The Short Circuit page in the Power Grid editor provides information necessary to model the utility grid as a source for studies including Short Circuit and Transient Stability. Relevant data include line voltage, shortcircuit MVA, three phase fault currents, and X/R ratios.

The Impedance elements in ETAP are utilized to model $10 \Omega$ resistors and $45 \mathrm{mH}$ inductors existing in the Cal Poly microgrid. The resistors in the microgrid are utilized for current-limiting purposes for safely testing power system faults. The inductors are utilized to model transmission lines of a power system. Although there exists a detailed Transmission Line and Reactor elements in ETAP, it is unnecessary in the modeling of inductors utilized in the microgrid.

The Power Transformer element in ETAP models twowinding three single-phase transformers in the Cal Poly microgrid with a 1:1 turns ratio rated at $3 \mathrm{KVA}, 240 \mathrm{~V}$, and $\mathrm{z}$ $=2.5 \%$. The transformers were included to more accurately model a complete power system and utilized for protective relaying test. Two power transformers are modeled connected in wye-wye configurations.

The Induction Machine element in ETAP models the three-phase induction motor. The ETAP element models the Hampden IM-100, a one-third horsepower three-phase, four pole, and squirrel cage motor with a wound stator and a squirrel cage rotor, utilized for loading purposes. Induction motor power and impedance parameters will play a role into short circuit and stability simulations. Due to resistive losses in the system, voltages applied at the terminals of the induction motor will be less than 208Vac in a laboratory setting. Induction motor parameters will be largely based on laboratory tested ratings rather than nameplate ratings.

The Static Load element in ETAP models two Hampden RLC-100 resistive/reactance loads utilized in the microgrid. The loads are connected in parallel, providing resistive loading controlled by 6 toggle switches (12 total), each one inserting a $2000 \Omega$ resistor in parallel in each leg simultaneously (to a minimum of $167 \Omega$ ). That is, at maximum loading the two three-phase static loads consume a total of

$$
P_{\max }=\frac{2 * 3 *\left(120 V_{L L}\right)^{2}}{333 \Omega}=259 \mathrm{~W}
$$

at a nominal 208Vac line-to-line. Due to resistive losses in the system, voltages applied to the static loads will be less than 208 Vac in a laboratory setting. Static load parameters will be largely based on laboratory tested ratings rather than nominal values.

The Synchronous Generator element in ETAP models two Hampden SM-100-3, three-phase, four pole machines consisting of a wye/delta stator and quadrature rotor having a DC field winding and a damper winding. DC field excitation is controlled by an external variable resistor (rheostat) supplied by $125 \mathrm{~V}$ DC. The rotor of the synchronous generator is driven by a DC machine, Hampden DM-100 providing one-third horsepower at $1800 \mathrm{rpm}$. SEL microprocessor based relays will be utilized to obtain oscillograms of the generator current and voltage characteristics, in which short circuit characteristics can be extracted.

The Relay elements in ETAP models Schweitzer Engineering Laboratory (SEL) microprocessor based protective relays include SEL-387E, SEL-311L, SEL-710, SEL-587, SEL-700G, and SEL-421 [4]. Current transformers (CTs) and potential transformers (VTs/PTs) shown in the ETAP model are utilized to feed SEL relays electrical quantities to determine the status of the microgrid. Due to low nominal and fault currents, the CTs and PTs are included in the one-line diagram to adhere with ETAP modeling standards, and do not exist in the hardware implementation. Therefore, the CTs and PTs throughout the ETAP model have a 1:1 turns ratio.

Figure 9 showcases a subsystem of the ETAP model where small scale solar photovoltaic generation complete with an inverter to interconnect with the microgrid is a logical addition to the system. ETAP consists of in depth solar photovoltaic and inverter modeling tools to accurately represent Cal Poly's renewable integration with the microgrid. ETAP is equipped with maximum power point tracking control capabilities with its solar inverters to adjust operating points for solar panels to extract maximum power. The SEL-751 in Fig. 9 can provide additional protective capabilities to the system [12].

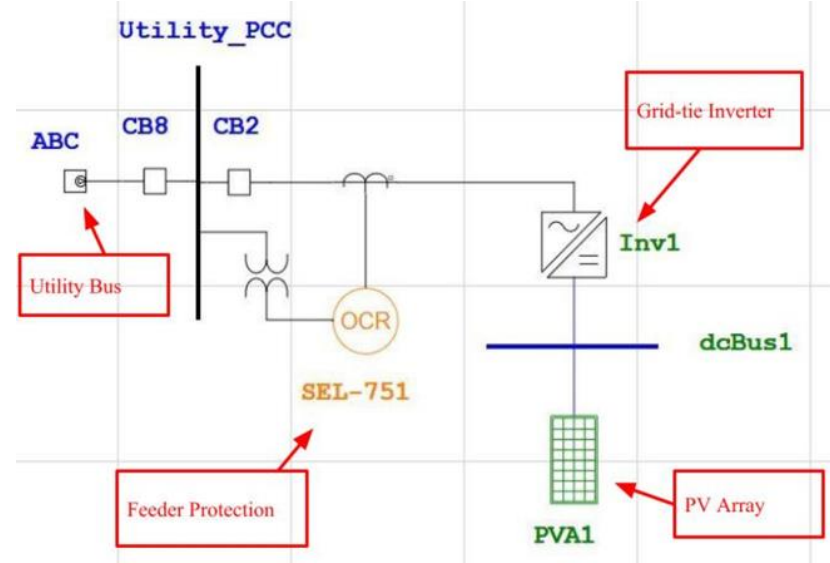

Fig. 9. ETAP microgrid sub-system. 
As an example, a PV module tentatively chosen for the Cal Poly microgrid modeling purposes is the SUNTECH STP210. Figure 10 displays the PV Array editor when double left clicking the PVA1 module in Fig. 9. Under the PV Panel page, the P-V curves display the power-voltage characteristics of a solar module for various levels of solar irradiance, a measure of energy in the form of sunlight. Similarly, the nonlinear I-V curves describe the currentvoltage characteristics of the solar cells for various levels of irradiance. ETAP has extensive libraries for various power system components, and the curves and parameters shown in Fig. 10 are populated when selecting the STP210 module from the library. Alternatively, a user can generate these curves individually by creating an ETAP PV Array library file given known equivalent circuit parameters of a solar cell, providing users with tools to accurately model a PV system.

The ETAP Inverter will be utilized to convert the DC characteristics from the PV array into the three-phase AC system, modeling the grid-tie inverter. The Inverter Editor can control and modify several parameters including converter's efficiency, generation for AC Load Flow calculations, and harmonics of the device. Power quality considerations can be analyzed by harmonics analysis tools in ETAP, and Fig. 11 displays the Harmonic tab of the gridtied inverter. The harmonics of a specific device can be chosen from a list of libraries in ETAP or entered given device characteristics.

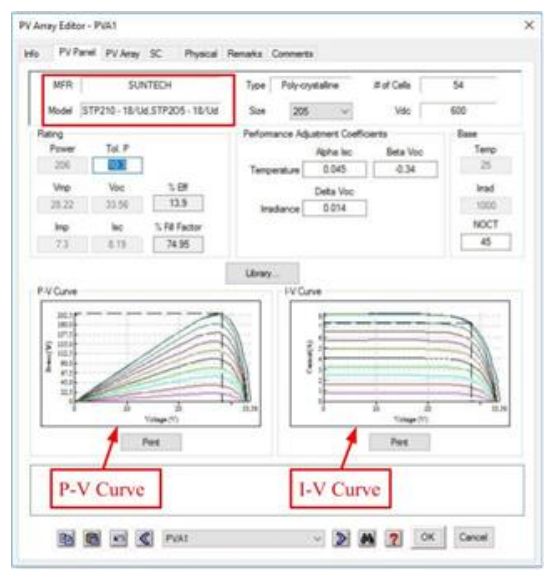

Fig. 10. PV array editor.

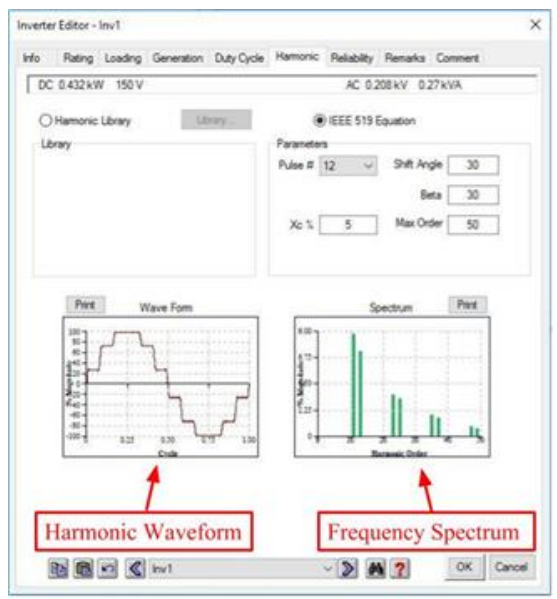

Fig. 11. Inverter editor.

Additionally, energy storage systems can be appended as additional generation and loading systems. Additional SEL relays can be utilized with solar integration to provide a more dynamic element to the system. That is, SEL relays can continually sense electrical quantities including voltages, currents, and frequencies from a PV subsystem to determine if curtailment or generation of renewable energy is necessary [13]. This can further lead to stability improvement methods, with control of power electronics providing many advantages to the microgrid.

For the load flow analysis, the purpose is to determine the balanced three-phase steady state operation of the Cal Poly microgrid. The load flow study will be performed in ETAP to meet the microgrid requirements of generation adequately supplying the demand (load) and losses, bus voltages close to nominal values, generation operating within active and reactive power limits, and transmission line (inductor) and transformers not overloaded [11]. Equipment operating values against manufacturer's specified maximum capability ratings will be compared when available.

The load flow study will consider several different operation scenarios such as maximum loading, minimum loading, normal loading, grid-connected, and islanded conditions. The Loading tab of the Load Flow Study Case editor shows Generation Category operating under Design. This forces the Load Flow study to consider all generating units in ETAP to operate under their Design operating conditions. For example, if we double left click a synchronous generator in the ETAP one-line, we open the Synchronous Generator Editor whose Design category is set to operate at $0.2 \mathrm{~kW}$ and $0.05 \mathrm{kvar}$, illustrated in Fig. 13. The Synchronous Generator is set to operate under Mvar Control instead of Swing Control in the Info page (not shown), to set fixed active and reactive power output of the machines. This will be useful as we can perform accurate case studies for generators outputting specific active and reactive power. Additionally, this is also due to the inherent limitations of the microgrid in which we do not implement generator exciter and governor control.

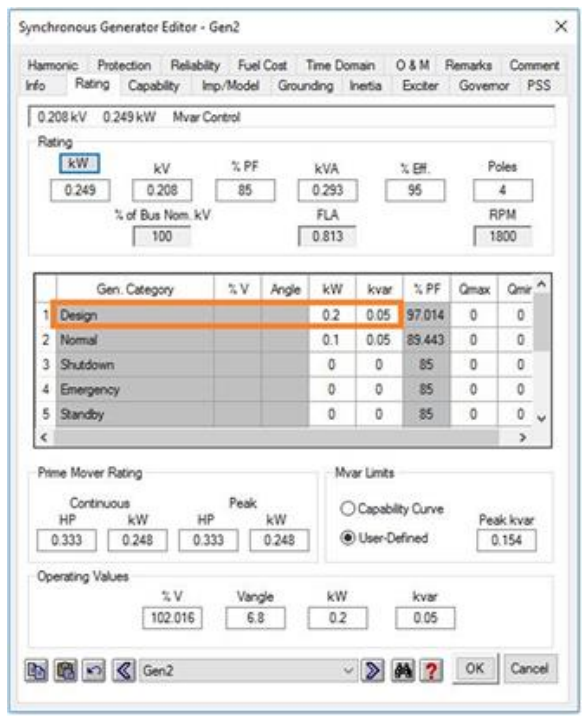

Fig. 12. Synchronous generator editor.

The main purpose of a short circuit study in the context of the Cal Poly microgrid lab is to ultimately determine appropriate ratings and settings for protective relay coordination by analyzing the effect of different faults injected in the system. Short circuit studies enable 
verification of protective device interrupting capabilities (e.g. circuit breakers), as well as protect equipment from large electromagnetic and mechanical forces due to high fault currents. However, fault currents in the Cal Poly microgrid are deliberately minimized due to safety considerations, and as a result of utilizing smaller rated equipment (e.g. 1/3rd horsepower motors and generators). ETAP elements that contribute to a short-circuit fault current include synchronous machines, induction machines, and the power (utility) grid. Additional modifications to the microgrid including inverters and batteries will also contribute to short-circuit currents.

\section{Simulation AND Test VALidation}

Figures 13 and 14 display the hardware and ETAP implementation of the microgrid system, separated between two different sections.

\section{A. Case 1: Bidirectional System, No Motor \& Capacitor}

Table I displays laboratory measured data of the microgrid to gather load flows throughout the system obtained from a previous study [14]. In this scenario the excitation voltage and the output power of the generator is manually adjusted by setting the speed of the prime mover (DC motor). Each synchronous generator is operating at 100W, 12Var, supplying a total of $200 \mathrm{~W}$ and $24 \mathrm{Var}$.
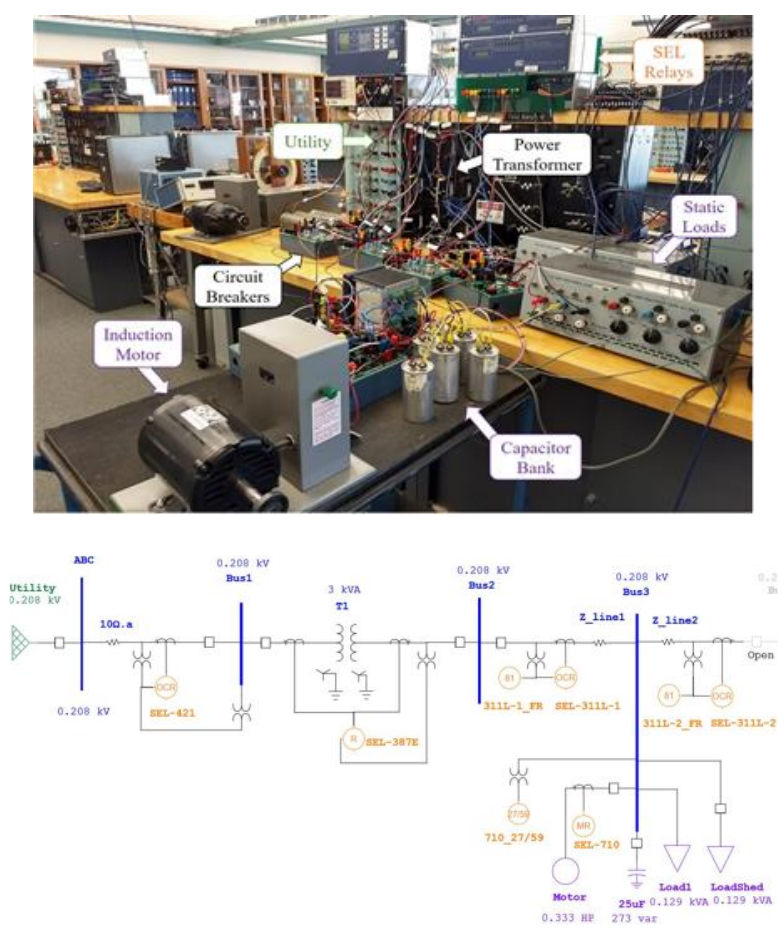

Fig. 13. Utility to Bus 3 hardware lab setup (top) and ETAP model (bottom).

Figure 15 provides a load flow comparison of a one-line depicting the apparent power (VA) and amps (A) flowing throughout the system. All sources of generation are selected to operate in swing mode. The utility supplies the power flowing from Bus 2 to Bus 3, and the generators supply the power flowing from Bus 4 to Bus 3. De-energized elements are grayed out (motor and capacitor).
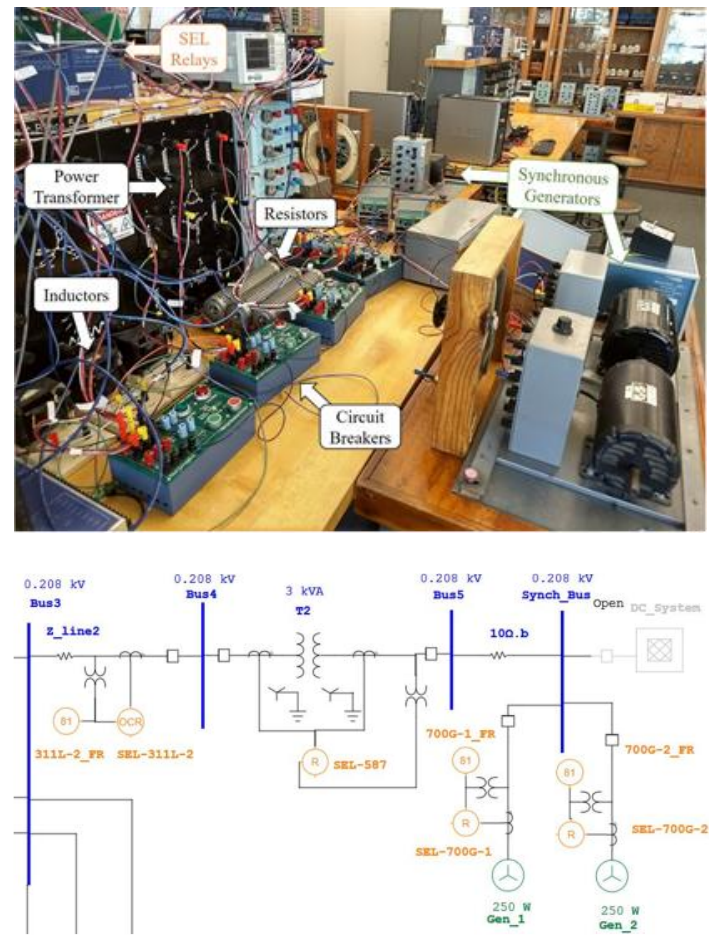

Fig. 14. Generator to Bus 3 hardware lab setup (top) and ETAP model (bottom).

TABLE I. SYSTEM SYNCHRONIZED, NO MOTOR, NO CAPACITORS

\begin{tabular}{lcccccc}
\hline Location & $\begin{array}{c}\text { Real } \\
\text { Power } \\
{[\mathrm{W}]}\end{array}$ & $\begin{array}{c}\text { Current } \\
{[\mathrm{A}]}\end{array}$ & $\begin{array}{c}\text { Voltage } \\
{[\mathrm{V}]}\end{array}$ & $\begin{array}{c}\text { Reactive } \\
\text { Power } \\
{[\mathrm{VAR}]}\end{array}$ & $\begin{array}{c}\text { Apparent } \\
\text { Power } \\
{[\mathrm{VA}]}\end{array}$ & $\begin{array}{c}\text { Power } \\
\text { Factor }\end{array}$ \\
\hline Generator & 200 & .563 & 208 & 24 & 235 & .857 \\
Utility & 133.8 & .369 & 207.6 & 54.6 & 152.6 & .739 \\
Motor & 0 & 0 & 194 & 0 & 0 & 1 \\
\hline
\end{tabular}

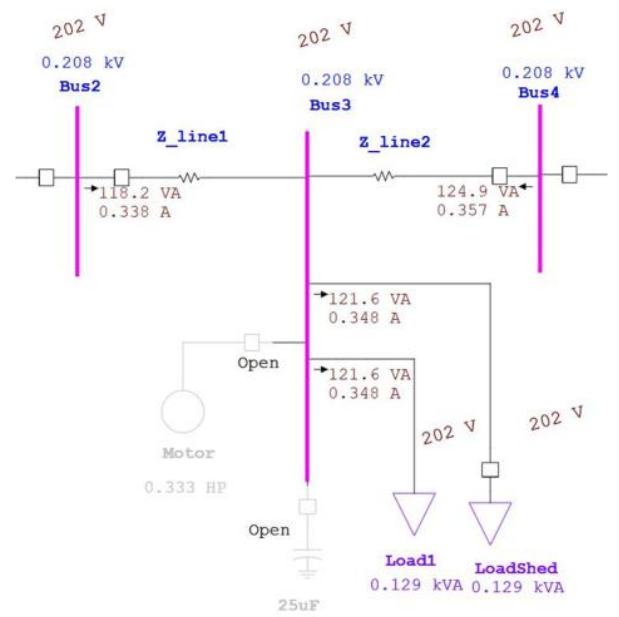

Fig. 15. Load flow for Case 1.

In Fig. 15, the total current supplied to the static loads at Bus 3 is 0.696 A. However, laboratory tested data in Table I suggests total current from utility and the generators supply about $0.932 \mathrm{~A}$. The discrepancies between the two data can be attributed to transformer magnetizing current and saturation, both of which are not modeled in ETAP. 
Consider Fig. 16 in which the synchronous generators are instead operated in Mvar mode, where the user can enter specific values of active and reactive power generation from the rating page of the synchronous generator models. The utility is still selected as swing mode, supplying the remaining power and balancing load flow in the system. We can observe that the power flowing from Bus 4 to Bus 3 from the generators closely matches that of Table 5-1 of $200 \mathrm{~W}$ and 24 Var.

However, we have compromised the remaining power flowing from the utility in this configuration. This is the inherent limitation of ETAP load flow modeling of non-ideal components largely due to the transformers drawing additional current throughout the system. Therefore, even if the generators are modified to supply specific fixed amounts of reactive and active power, the ETAP model will not accurately represent the hardware representation of the system, and there will be less total power flowing in the system when compared to laboratory data.

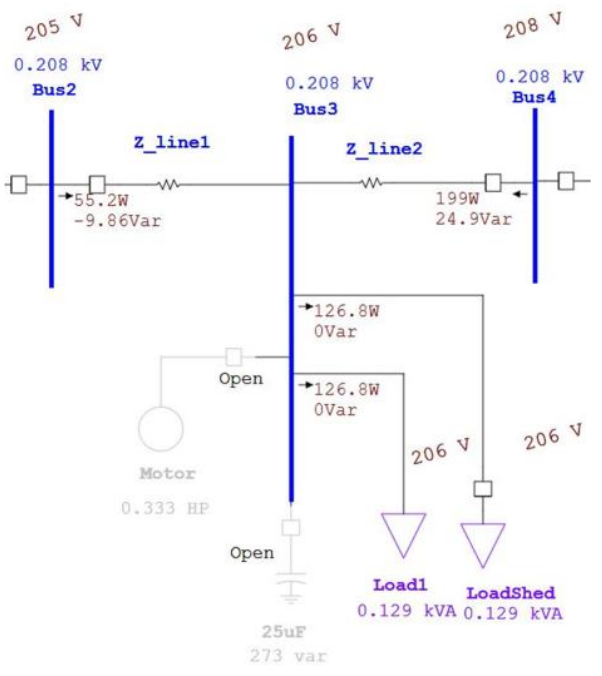

Fig. 16. Load flow for Case 1 in MVAR mode

\section{B. Case 2: Bidirectional System with Motor \& Capacitors}

Table II showcases microgrid system data with the motor and capacitor both turned on [14].

TABLE II. SYSTEM SYNCHRONIZED WITH MOTOR \& CAPACITORS

\begin{tabular}{lcccccc}
\hline Location & $\begin{array}{c}\text { Real } \\
\text { Power } \\
{[\mathrm{W}]}\end{array}$ & $\begin{array}{c}\text { Current } \\
{[\mathrm{A}]}\end{array}$ & $\begin{array}{c}\text { Voltage } \\
{[\mathrm{V}]}\end{array}$ & $\begin{array}{c}\text { Reactive } \\
\text { Power } \\
{[\mathrm{VAR}]}\end{array}$ & $\begin{array}{c}\text { Apparent } \\
\text { Power } \\
{[\mathrm{VA}]}\end{array}$ & $\begin{array}{c}\text { Power } \\
\text { Factor }\end{array}$ \\
\hline Generator & 200 & .6 & 208 & 130 & 250 & .799 \\
Utility & 184.9 & .562 & 206.4 & 58.5 & 232.5 & .797 \\
Motor & 76.9 & .268 & 187 & 40 & 87 & .00 \\
\hline
\end{tabular}

Figure 17 displays the load flow with all generations as swing buses for purposes of simulation. Power flow between Bus 4 and Bus 3 from the generators and between Bus 2 and Bus 3 from the utility results in a smaller current than that shown in Table II. This is again due to the inherent limitation of limited reactive power flow in the system as mentioned in Case 1 of load flow analysis. Next we apply a wye-connected capacitor bank of $25 \mu \mathrm{F}$ each energized at $185 \mathrm{~V}$ line-to-line supplying a total of 323 Var at the motor bus, shown in Fig. 17. Bus voltages are increased by providing reactive power support to the system. Additionally, the lowering of apparent power and current is seen from Bus 2 to Bus 3 and Bus 4 to
Bus 3, which are the apparent power and current flow from the utility and generators, respectively.

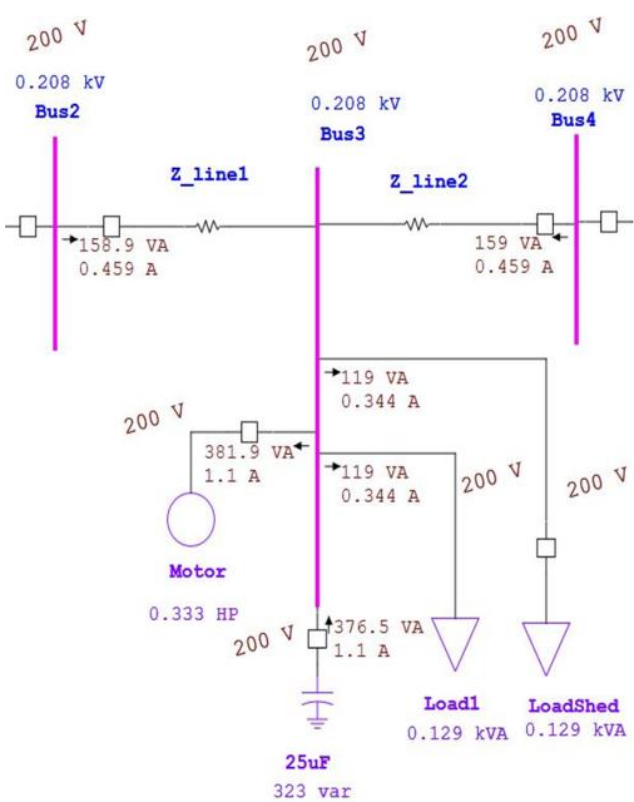

Fig. 17. Load flow for Case 2 .

\section{Case 3: DC Load Flow}

Case 3 of Load Flow analysis considers some of the capabilities and possibilities of running DC load flow simulations. The future microgrid lab will utilize BP SX $150 \mathrm{~S}$ Solar Panels rated at $150 \mathrm{~W}$, open circuit voltage of $43.5 \mathrm{~V}$, short circuit current of $4.75 \mathrm{~A}$, maximum power point operating voltage at $34.5 \mathrm{~V}$, and maximum power point current of $4.35 \mathrm{~A}$. The inverter to connect to the $\mathrm{AC}$ system will be the APsystems 1000W YC-1000 3-phase microverter [15]. For purposes of simulations, the Photowatt PV1400 will be used as a model in ETAP for conduction DC Load Flow, rated at $150 \mathrm{~W}$, maximum power point operating voltage at $33.69 \mathrm{~V}$, and maximum power point current of 4.45 A, which closely model the BP SX 150S.

Solar panel ratings are provided based on standard test conditions and several conditions such as solar irradiation, module temperature, angle with respect to the sun and others as presented in [16]. For purposes of simulations we utilize standard test conditions of 25 degrees Celsius, and set an irradiance of $200 \mathrm{~W} / \mathrm{m}^{2}$ for four PV1400 panels, with a DC load flow shown in Figure 18.

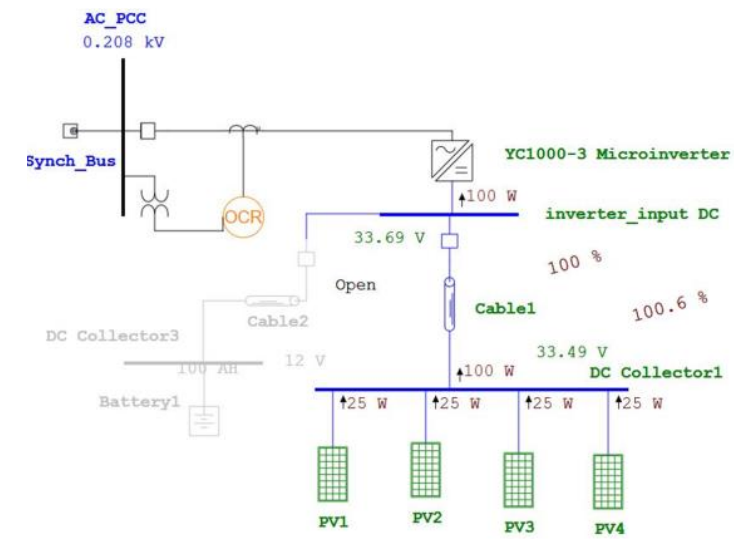

Fig. 18. DC load flow for Case 3 . 
The inverter can be operated as MVAR controlled AC operation mode, similar to that of the synchronous generators. With a $95 \%$ efficiency, we can specify the AC output to be $95 \mathrm{~W}$, or any specific fixed amount of the input DC power from the solar panels. Cable impedance is neglected for purposes of simulation, but can be entered if losses are needed. This shows the capabilities of the DC load flow: ability to investigate different PV generating parameters and determine output $\mathrm{AC}$ power and supply known power to the microgrid accordingly. Figure 19 displays an AC Load Flow taking into account the DC power supplied by the panels. The generators are heavily relieved from the active power demanded from the system, supplemented from solar generation. The synchronous generators instead provide mostly reactive support to the system. The generators and utility are operating in swing mode, while the inverter is operating in MVAR with fixed output of $95 \mathrm{~W}$. The motor is turned on, with the capacitor off. The DC_system subsystem block in Fig. 19 contains the DC system depicted in Fig. 18.

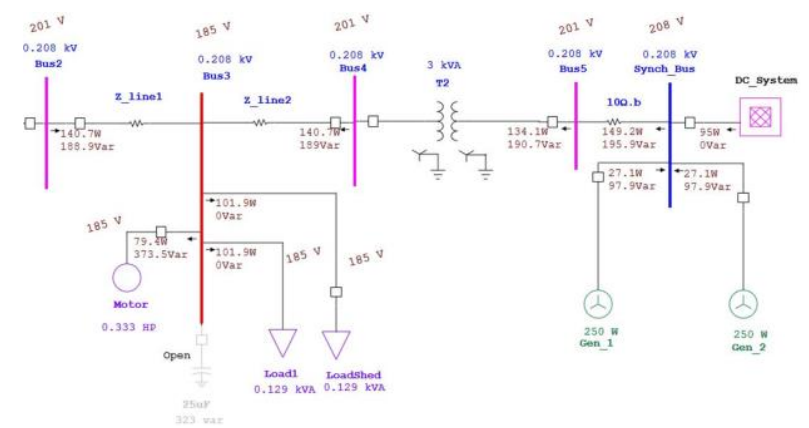

Fig. 19. AC load flow with PV generation.

\section{CONCLUSION}

Advancements in renewable energy technologies along with their decreasing costs and renewable energy mandates are shifting the power industry away from the centralized generation model and instead incorporate distributed energy resources close to end users to meet the electrical demands of the customer. The modern microgrid has capabilities of operating in both islanded and grid-connected modes to help supplement the transfer of energy. This paper describes the development of an ETAP model of a lab-scale microgrid currently developed at Cal Poly State University and test its load flow performance. Several case studies and system validations comparing the ETAP model with the Cal Poly microgrid were conducted, showcasing the powerful analysis tools ETAP can offer. Successful replication of both short circuit and protection coordination studies were validated for both the hardware and ETAP implementations of the microgrid.

Cases I-III of Load Flow analysis considered different variations of the bidirectional microgrid system. In all cases, total power supplied from generation is lower than the hardware implementation of the microgrid. This is due to inherent limitations of the Load Flow analysis module which does not consider the effects of transformer magnetizing current and saturation. Case III also considered the DC Load Flow in which PV panels were utilized to supplement active power in the system. The future microgrid can vary the amount of panels based on power demand, and utilize the generator(s) for reactive power support.
Load flow and transient stability studies were the most difficult studies to accurately model the Cal Poly microgrid due to several considerations: non-ideal low rated equipment, low time constants associated with dampening of transients, and low system inertia. Magnetizing current and transformer saturation could not be modeled in ETAP load flow analysis, resulting in less current flowing throughout the system and higher overall bus voltages. ETAP is originally designed to model industrial scale and larger power systems, whereas the rotating machineries in the $\mathrm{Cal}$ Poly's microgrid lab are rated at one-third horse power with very low rotational inertia.

\section{REFERENCES}

[1] “The Utility View Of Microgrids," Utility Dive. 2014.

[2] A. Majzoobi and A. Khodaei, "Application of microgrids in providing ancillary services to the utility grid," Energy, vol. 123, pp. 555-563, Mar. 2017.

[3] P. Denholm, M. O'Connell, G. Brinkman, and J. Jorgenson, "Overgeneration from Solar Energy in California: A Field Guide to the Duck Chart," National Renewable Energy Laboratory, Golden, CO, 2015.

[4] K. Pretzer, "Protective Relaying Student Laboratory," Master's Thesis, Dept. Elect. Eng., California Polytechnic State Univ., San Luis Obispo, 2017

[5] P. Kundur et al., "Definition and classification of power system stability IEEE/CIGRE joint task force on stability terms and definitions," IEEE Transactions on Power Systems, vol. 19, no. 3, pp 1387-1401, Aug. 2004

[6] R. Majumder, "Some Aspects of Stability in Microgrids," IEEE Transactions on Power Systems, vol. 28, no. 3, pp. 3243-3252, Aug. 2013.

[7] R. Singh and M. Kirar, "Transient stability analysis and improvement in microgrid," in 2016 International Conference on Electrical Power and Energy Systems, Bhopal, 2016, pp. 239-245.

[8] P. Kundur, N. J. Nalu, and M. G. Lauby. Power System Stability and Control. New York: McGraw-Hill, 1994. Print.

[9] J. McCalley. EE 554. Class Lecture, Topic: "Preliminary Fundamentals." College of Engineering, Iowa State University, Ames, Iowa, Spring 2009

[10] ETAP 14.1 User Guide. Operation Technology, Inc.

[11] J. D. Glover, T.J. Overbye, and M.S. Sarma, Power system analysis and design, 5th ed. Stamford, CT: Cengage Learning, 2012. Print.

[12] A. Shaban, and A. Nafisi. EE 518. Class Lecture, Topic: "Symmetrical Components." College of Electrical Engineering, California Polytechnic State University, San Luis Obispo, San Luis Obispo, California, Spring 2017

[13] J. L. Blackburn and T. J. Domin, Protective Relaying: Principles and Applications, 3rd ed. FL: CRC Press, 2006. Print.

[14] C. Osborn, "Microgrid Laboratory," Master's Thesis, Dept. Elect. Eng., California Polytechnic State Univ., San Luis Obispo, In Progress.

[15] APsystems YC1000-3 Microinverter Datasheet, APsystems, Seattle, WA, June 13, 2017. Available: http://usa.apsystems.com/wpcontent/uploads/2017/07/APsystems-YC1000-Datasheet-7.20.17.pdf

[16] Yang, Woo-Sik "Microgrid Laboratory," Senior Design Project, Dept. Elect. Eng., California Polytechnic State Univ., San Luis Obispo, 2018 .

\section{BIBLIOGRAPHY}

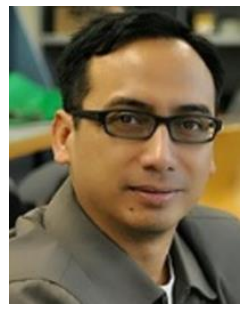

Taufik received his BS in Electrical Engineering with minor in Computer Science from Northern Arizona University, MS in Electrical Engineering from University of Illinois Chicago, and Doctor of Engineering from Cleveland State University. He is currently a Professor and the Director of Electric Power Institute at Cal Poly State University in San Luis Obispo. He is a Senior Member of IEEE and has industry experience with engineering companies including Capstone Microturbine, Rockwell 
Automation, Picker International, San Diego Gas \& Electric, Diodes Inc., Enerpro, and Sempra Energy. He has published over 200 technical papers and journals, reports, books, course readers, and served on the editorial review boards of several journals. His areas of research include power electronics, power systems, energy harvesting and renewable energy.

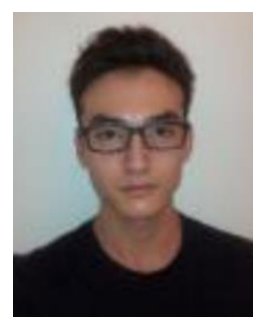

Matthew Guevara received his BS in Electrical Engineering from California State University at Northridge, and in 2018 graduated with MS in Electrical Engineering from Cal Poly State University in San Luis Obispo. He is currently an electrical engineer at Los Angeles Department of Water and Power. His interest is in the broad area of power systems and power electronics.

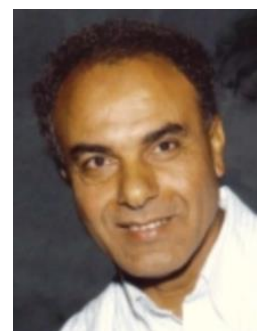

Ali Shaban received his Ph.D. degree in Electrical Engineering from Oregon State University in 1985. He joined the Electrical Engineering Department at Cal Poly in 1984. Since 1985, he has done consulting work with Chevron, Southern California Edison, JPL Scientific, and Bluepoint Associates, Ltd., in San Luis Obispo. His field of interest is electric machines, power quality, power systems analysis, and power systems protection. He has published in the areas of synchronous machines, induction motor, reliability, and power quality. He is a member of the IEEE and PES.

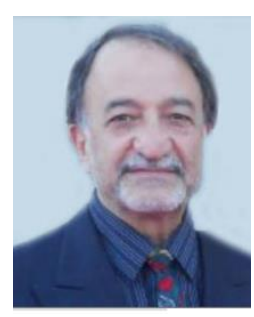

Ahmad Nafisi received his Ph.D. degree in Electrical Engineering from University of Southern California in 1983. He joined the Electrical Engineering Department at Cal Poly in 1984. He has done consulting and research activities with Electro-Kinesis, Inc. (a Division of Superior Electric Company), Southern California Edison, PG\&E, and Los Angeles Department of Water and Power. He was the director of Cal Poly Electric Power Institute from 1998-2010. His field of interest are electric machines, power systems analysis, power quality, and magnetic materials. He is a member of the IEEE and PES. 